\title{
WORKSHOP DISPLAY KELAS UNTUK MENINGKATKAN MOTIVASI SISWA DALAM MENGIKUTI PELAJARAN IPS SE-KECAMATAN LAMPIHONG
}

\author{
Syarifuddin \\ Sekolah Tinggi Ilmu Alquran (STIQ) Amuntai \\ Jl.Rakha Pakapuran, Panangkalaan, Amuntai Utara, Kabupaten Hulu Sungai Utara, \\ Kalimantan Selatan \\ Email: Syarifuddin.stiq@gmail.com
}

\begin{abstract}
Workshop activities like this really help teachers in developing students' imaginative abilities, and can increase students' motivation to always attend school, because schools become interesting and full of students' work with teachers. The materials used for making displays are very easy to obtain, so there are no more obstacles in their implementation. Teachers are assisted by KKN students in planning, making and displaying displays.
\end{abstract}

Keywords: creative; creation; collaboration; IPS

\begin{abstract}
Abstrak. Kegiatan workshop seperti ini sangat membantu guru-guru dalam mengembangkan kemampuan imajinasi peserta didik, serta dapat menambah motivasi peserta didik untuk selalu hadir ke sekolah, karena sekolah menjadi menarik dan penuh dengan karya peserta didik bersama guru. Bahan-bahan yang digunakan untuk pembuatan display sangat mudah didapatkan, sehingga tidak ada lagi kendala dalam pelaksanaannya. Guru-guru dibantu oleh mahasiswi KKN dalam merencanakan, membuat dan memajang display.
\end{abstract}

Kata Kunci: kreatif; karya; kolaborasi; IPS

I majinasi seseorang akan muncul saat ia melihat sesuatu yang berbeda seperti warnawarni. Untuk menumbuhkan semangat peserta didik dalam mendapatkan imajinasi maka perlu dibuat suasa kelas yang berbeda dari biasanya. Suatu hal yang bisa membuat kelas berbeda adalah mendisplaykelas. Guru bisa mengajak peserta didik untuk membuat display. Beberapa manfaat untuk display adalah kelas yang tertata dengan baik mampu menciptakan suasana kondusif dalam proses pembelajaran. Selain itu juga ada beberapa manfaat display kelas, selain fungsi untuk keindahan juga dapat mengoptimalkan proses pembelajaran. Display dalam artiannya adalah alternatif yang digunakan dalam pembelajaran di sekolah (Syadiah dkk., 2017, hlm. 18). Ketika mendisplay kelas ada beberapa hal yang perlu diperhatikan seperti: pemilihan warna, tempat dan bahan yang 
digunakan, kesesuaian dengan kelas dan tingkatan, mengandung unsur pelajaran, bahan yang murah dan mudah didapat dan lain-lain.

Display kelas yang menarik akan menumbuhkan motivasi peserta didik dalam mengikuti pelajaran. Motivasi menurut Hamalik adalah perubahan energi dalam diri pribadi seseorang yang ditandai dengan timbulnya perasaan dan reaksi untuk mencapai tujuan(A Octavia, 2020, hlm. 52). Motivasi terbagi menjadi dua internal dan eksternal. Internal adalah motivasi siswa yang tumbuh dari dalam dirinya sendiri, seperti belajar karena ingin mendapatkan ilmu dan mengupgread diri agar menjadi lebih baik lagi. Sedangkan motivasi eksternal adalah motivasi yang didapat karena pengaruh lingkungan (Kusuma dkk., 2019, hlm. 28).

Betapa pentingnya motivasi terutama dalam proses pembelajaran juga untuk meningkatkan kualitas peserta didik itu sendiri. Cita-cita hidup hanya akan dapat diraih apabila memiliki motivasi yang kuat dalam diri(Dayana \& Marbun, 2018, hlm. 15). Bahkan sebenarnya tidak ada peserta didik yang malas, yang ada hannyalah peserta didik yang kurang motivasi.

Motivasi memiliki beberapa tingkatan sebagaimana yang dijabarkan oleh maslow terdiri atas lima lapisan: 1) kebutuhan fisiologis (sandang pangan); 2) kebutuhan rasa aman (papan, finansial); 3) kebutuhan akan cinta dan rasa memiliki (persahabatan, teman hidup, berkeluarga); 4) kebutuhan akan penghargaan (status, gelar, jabatan); dan 5) kebutuhan aktualisasi diri (puas dalam usaha, menemukan makna dalam pekerjaan, menikmati keindahan)(Suharjo \& Cahyono, 2011, hlm. 8). Dalam ranah pendidikan perlu untuk dikembangkan dan didorong motivasi peserta didik untuk meraih nilai yang baik, agar nantinya mampu untuk bersaing ketika melanjutkan sekolah yang lebih tinggi lagi.

Materi pelajaran yang sering terlupakan adalah mata pelajaran IPS. Terkadang peserta didik tidak termotivasi untuk mengikuti pelajaran dikarenakan guru dalam memberikan materi terkadang sedikit menggunakan contoh media bahkan hampir dikatakan tidak pernah(Puspitorini \& Jamal, 2019, hlm. 49). Oleh sebab itulah terkadang peserta didik menjadi lemah motivasinya untuk mengikuti pelajaran IPS, namun setelah guru memanfaatkan media gambar aktivitas motivasi peserta didik menjadi meningkat(Syarifuddin, 2019, hlm. 51).

Jadi, tujuan dalam workshop ini meningkatkan motivasi peserta didik untuk mengikuti pelajaran IPS khususnya dan mata pelajaran selain IPS pada umumnya. 


\section{METODE}

Kegiatan pelatihan dilaksanakan di SDN Kusambi Hulu Kecamatan Lampihong, Kalimantan Selatan Pada tanggal 17 November 2018. Tempat pelatihan dilaksanakan di lokal kelas. Jumlah peserta sebanyak 25 orang terdiri dari guru dan merupakan perwakilan dari berbagai sekolah yang ada di kecLampihong. Bentuk dalam kegiatan berupa pemberian materi tentang display dan dilanjutkan dengan pembuatan display kelas. Materi yang diberikan bisa dilihat pada tabel 1 di bawah ini:

Tabel 1. Materi Workshop Display

\begin{tabular}{|c|c|c|c|c|}
\hline No & $\begin{array}{l}\text { Standar } \\
\text { Kompetensi }\end{array}$ & $\begin{array}{l}\text { Kompetensi } \\
\text { Dasar }\end{array}$ & Tujuan & Indikator \\
\hline 1 & & $\begin{array}{l}\text { Mengetahui } \\
\text { konsep dan } \\
\text { fungsi display }\end{array}$ & $\begin{array}{lr}\text { Dengan } & \text { kuis } \\
\text { guru } & \text { dapat } \\
\text { menyebutkan } & \\
\text { konsep r dan } \\
\text { fungsi } \\
\text { kelas }\end{array}$ & $\begin{array}{l}\text { Dapat menyebutkan konsep } \\
\text { dan fungsi display }\end{array}$ \\
\hline 2 & $\begin{array}{l}\text { Mengaplikasikan } \\
\text { display dalam } \\
\text { pembelajaran IPS }\end{array}$ & $\begin{array}{l}\text { Memahami } \\
\text { konsep dan } \\
\text { fungsi display }\end{array}$ & $\begin{array}{l}\text { Dengan } \\
\text { powerteaching } \\
\text { guru mampu } \\
\text { menjelaskan } \\
\text { konsep dan } \\
\text { fungsi display } \\
\text { dengan tepat }\end{array}$ & $\begin{array}{l}\text { Dapat menjelaskan konsep dan } \\
\text { fungsi display }\end{array}$ \\
\hline 3 & & $\begin{array}{l}\text { Mengaplikasikan } \\
\text { display dalam } \\
\text { kelas }\end{array}$ & $\begin{array}{l}\text { Dengan praktik } \\
\text { guru mampu } \\
\text { mengaplikasikan } \\
\text { display dalam } \\
\text { pembelajaran di } \\
\text { kelas secara } \\
\text { kreatif }\end{array}$ & $\begin{array}{l}\text { Dapat } \\
\text { mengapklikasikandisplaydalam } \\
\text { kelas }\end{array}$ \\
\hline
\end{tabular}

Pelaksanaan kegiatan pengabdian kepada masyarakat ini dilakukan dalam tiga step yaitu: step persiapan, step pelaksanaan dan step pelaporan. Step dilakukan agar dalam pelaksanaannya menjadi terarah dan dapat terlaksana dengan baik. Stepnya bisa dilihat pada tabel 2 di bawah ini: 
Tabel 2. Step by Step Worhshop Display

\begin{tabular}{|c|c|c|c|c|c|}
\hline \multicolumn{2}{|r|}{ Step Persiapan } & \multicolumn{2}{|r|}{ Step Pelaksanaan } & \multicolumn{2}{|r|}{ Tahap Akhir } \\
\hline 1 & Observasi lapangan & 1 & $\begin{array}{l}\text { Tes awal pemahaman guru } \\
\text { tentang Display }\end{array}$ & 1 & $\begin{array}{l}\text { Mendampingi guru dalam } \\
\text { merancang serta membuat } \\
\text { display }\end{array}$ \\
\hline 2 & Konfirmasi lapangan & 2 & $\begin{array}{l}\text { Memberikan materi tentang } \\
\text { pembuatan display }\end{array}$ & 2 & $\begin{array}{l}\text { Mempresentasikan hasil } \\
\text { display yang telah dibuat } \\
\text { bersama-sama }\end{array}$ \\
\hline 3 & $\begin{array}{l}\text { Membentuk tim } \\
\text { pelaksana }\end{array}$ & 3 & $\begin{array}{l}\text { Membuat display bersama- } \\
\text { sama }\end{array}$ & 3 & Mengevaluasi kegiatan \\
\hline 4 & $\begin{array}{l}\text { Merancang proposal } \\
\text { workshop }\end{array}$ & 4 & $\begin{array}{l}\text { Tes akhir pemahaman guru } \\
\text { tentang display } \text { yang } \\
\text { berhubungan } \\
\text { pelajaran IPS }\end{array}$ & 4 & $\begin{array}{l}\text { Membuat } \\
\text { workshop }\end{array}$ \\
\hline
\end{tabular}

Pelaksanaan kegiatan saat workshop dibantu oleh 6 orang mahasiswi KKN dalam membuat display kelas, berkolaborasi dengan guru-guru agar display sesuai dengan materi Ilmu Pengetahuan Sosial.

\section{HASIL DAN PEMBAHASAN}

Pada kegiatan workshop didahului dengan menampilkan pada layar tentang perbandingan kelas yang sudah dihias dengan display dan yang belum dihias dengan display. Kemudian dilanjutkan dengan menjelaskan pengertian display. Display adalah tempat atau wadah untuk informasi penting yang dapat menunjang proses pembelajaran di kelas lalu dilanjutkan dengan memberikan penjelasan dengan apa tujuan dan fungsi display.

Tujuan dan fungsi display adalah sebagai berikut: 1) sebagai tempat menempel berbagai jenis hasil pekerjaan atau hasil karya peserta didik; 2) sebagai bentuk penghargaan atas upaya yang telah dilakukan oleh peserta didik dalam menyelesaikan sebuah tugas atau pekerjaan; 3) meningkatkan motivasi peserta didik, karena betapa pun kualitas kerja yang dihasilkan akan mendapat kesempatan yang sama untuk dapat dipajang; 4) sebagai tempat informasi, yang bersifat umum, seperti poster atau slogan, maupun yang terkait dengan pembelajaran, seperti bagan/chart/ grafik, langkah kerja/rumus, dsb; 5) bertujuan untuk menghiasi kelas dan memperindahnya; 6) sebagai bahan evaluasi bagi dan peserta didik serta orang tua melalui tampilan/pajangan yang tertera pada papan display. Misalnya bagi guru melalui pajangan peserta didik dapat melihat sendiri hasil nilai kegiatan belajar antara sesama peserta didik, sedangkan bagi peserta didik dapat mengukur seberapa kemampuan mereka dibandingkan dengan peserta 
didik lainnya. Adapun bagi orang tua dapat melihat secara langsung kemajuan dari putra/i dalam meningkatkan kualitas kerjanya; dan 7) karena sering kali papan display bisa dianggap sebagai semi portofolio, maka display juga bertujuan menampilkan hasil kerja peserta didik.

Berikutnya menjelaskan beberapa jenis display kelas seperti display untuk informasi, display evaluasi, display pembelajaran, display pemandangan/keindahan, display motivasi. Kemudian dilanjutkan dengan mengajarkan teknik mendisplay. Ada tiga bagian teknik dalam mendisplay1) perencanaan; 2) membuat display; dan 3) memajang hasil karya. Pertama perencanaan, tahap ini guru harus dapat menjawab dari dua pertanyaan. Apakah display yang akan dibuat dapat menarik peserta didik untuk melihat dan membaca dan hasil karya peserta didik seperti apa yang akan dijadikan display. Berikut adalah tabel dalam perencanaan, membuat serta memajang display.

Tabel 3. Perencanaan, Membuat dan Memajang display

\begin{tabular}{|c|c|c|}
\hline Tanggal & : & 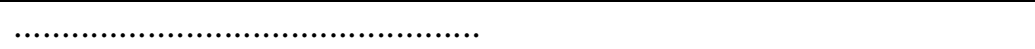 \\
\hline Mata Pelajaran & : & 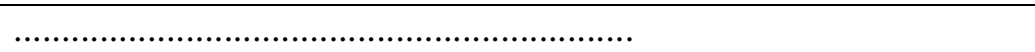 \\
\hline Kelas & : & .................... \\
\hline Semester & $:$ & .................. \\
\hline Judul/tema display & : & 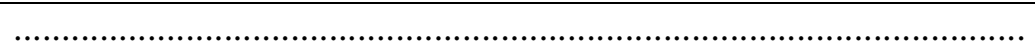 \\
\hline \multicolumn{3}{|l|}{ Uraian materi } \\
\hline \multicolumn{3}{|c|}{ (1) } \\
\hline \multicolumn{3}{|c|}{ Peralatan dan perlengkapan yang digunakan } \\
\hline \multicolumn{3}{|c|}{ 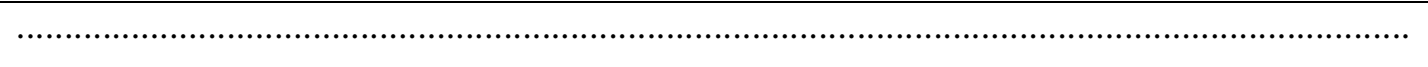 } \\
\hline \multicolumn{3}{|c|}{ Langkah-langkah pembuatan } \\
\hline \multicolumn{3}{|c|}{ 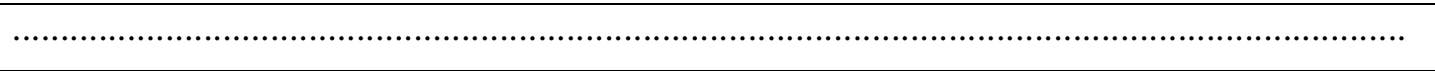 } \\
\hline \multicolumn{3}{|c|}{ Pajangan/hasil/gambar } \\
\hline
\end{tabular}

Selanjutnya dijelaskan bagaimana mendisplay kelas agar menjadi baik maka diberikan materi tentang kesesuaian seperti perpaduan warna, background serta garis tepi. Setelah semua dijelaskan dengan saksama maka dilanjutkan dengan sesi berikutnya membuat display dengan cara berkelompok. Guru dibagi menjadi lima kelompok dengan 
masing-masing anggota empat orang dengan didampingi mahasiswi KKN dalam pembuatan displaynya. Pada tahap akhir adalah persentasi hasil karya guru-guru dalam mendisplaydengan materi yang berhubungan dengan pelajaran IPS.

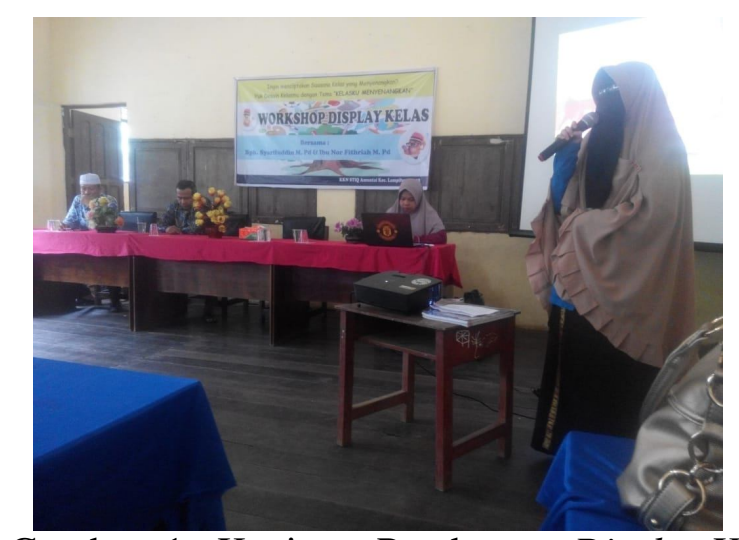

Gambar 1. Kegiatan Pembuatan Display Kelas

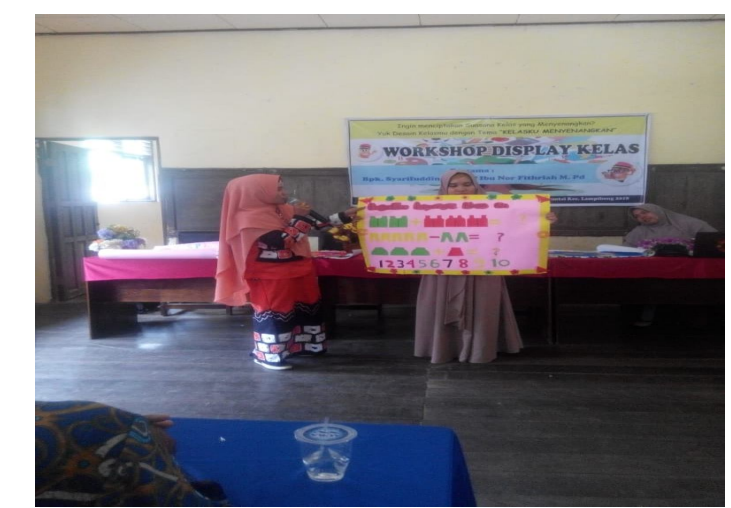

Gambar 2. Kegiatan Persentasi Display Kelas

\section{SIMPULAN}

Display kelas menjadikan ruangan tempat belajar yang mengasyikkan terlihat indah karena adanya display pemandangan, peserta didik pun dapat informasi dengan cepat karena adanya display informasi, berbagai materi pelajaran tersedia karena adanya display pembelajaran yang sesuai dengan kebutuhan peserta didik. Guru dan orang tua dapat memantau kemajuan peserta didik dalam belajar melalui display evaluasi.

\section{UCAPAN TERIMA KASIH}

Terima kasih diucapkan kepada kepala Sekolah Dasar Negeri SDN Kusambi Hulu, karena telah memfasilitasi tempat, proyektor, konsumsi hingga acara workshop bisa 
terlaksana dengan baik. Tak lupa diucapkan terima kasih kepada mahasiswa KKN Sekolah Tinggi Ilmu Alquran STIQ Amuntai yang sudah mau bekerja sama dengan pihak sekolah SDN Kusambi, bekerja menjadi panitia workshop, kami ucapkan juga terima kasih kepada teman dosen STIQ yang sudah mau menjadi partner dalam menyampaikan materi display kelas dan terakhir kami sampaikan terima kasih kepada seluruh guru-guru yang hadir dalam acara workshopdisplay kelas sehingga acara bisa terlaksana.

\section{DAFTAR PUSTAKA}

A Octavia, S. (2020). Motivasi Belajar Dalam Perkembangan Remaja. Deepublish.

Dayana, I., \& Marbun, J. (2018). Motivasi Kehidupan. GUEPEDIA.

Kusuma, Y., Kusuma, H. E., Tampubolon, A. C., \& Aryanti, T. (2019). Pengaruh Kualitas Lingkungan dan Motivasi pada Kinerja Akademik Siswa SMA. RUAS (ReviewofUrbanismandArchitecturalStudies), 16(2), 28-41.

Puspitorini, P., \& Jamal, A. N. (2019). PENGGUNAAN MEDIA GAMBAR TERHADAP PENINGKATAN HASIL BELAJAR IPS KELAS III A DI MIN 4 SERANG. Jurnal Pendidikan Dasar Setiabudhi, 2(2), 47-59.

Suharjo, J. B., \& Cahyono, B. (2011). Meraih Kekuatan Penyembuh Diri yang Tak Terbatas. Gramedia Pustaka Utama.

Syadiah, D. H., Putro, S., \&Indrayati, A. (2017). EFEKTIVITAS PEMBELAJARAN MENGGUNAKAN MEDIA DISPLAY MATERI PERMASALAHAN LINGKUNGAN HIDUP DAN PENANGGULANGANNYA SISWA KELAS VIII SMPN 10 SEMARANG TAHUN AJARAN 2016/2017. Edu Geography, $5(2), 18-25$.

Syarifuddin. (2019). Meningkatkan Hasil Belajar Peserta Didik pada Mata Pelajaran IPS Menggunakan Model Pembelajaran Picture and Picture. https://journal.iainsamarinda.ac.id/index.php/SAJIE/article/view/1657/pdf, 2(1), 51-66. https://journal. iain-samarinda.ac.id/index.php/SAJIE/issue/archive. 